\title{
CONCEPTUAL MODEL OF THE EDUCATIONAL PRESUMPTIONS OF THE COORDINATION OF COLLABORATION AND COMPETITION CAPABILITIES IN DANCESPORT
}

\author{
Audrius Armas, Šarūnas Šniras \\ Lithuanian Sports University, Kaunas, Lithuania
}

\begin{abstract}
Background. Simultaneously manifested collaboration and competition capabilities are coordinated. This harmony is determined by social interdependency of participants of the activity. It is also true about the dancesport activity. Dancesport dancers mostly compete for higher results, but collaboration is obligatory in order to achieve that result. The problem question was what the educational presumptions of the coordination of collaboration and competition in the dancesport activity are. The research aim was to create the conceptual model of the educational presumptions of the coordination of collaboration and competition in the dancesport activity.

Research method was theoretical analysis and synthesis. The results of theoretical analysis are generalized and incorporated into the conceptual model.

Discussion and conclusions. The theoretical model of the educational presumptions of the coordination of collaboration and competition in dancesport compiled and presented on the basis of the analysis of scientific literature reveals the conceptual basis of the educational presumptions of the coordination of collaboration and competition in dancesport. Dancesport dancers act and strive for sport and personal goals by using collaboration and competition capabilities, coordinating them and reaching the higher form of coopetition (harmony). The model of the educational presumptions of the coordination of collaboration and competition in dancesport is based on the analysis of literature about the forms of the interpersonal interaction both in the social environment and sport activity, manifestation of discussed forms of the interaction and theory of empiric learning including capabilities.
\end{abstract}

Keywords: collaboration, competition, coopetition, dancesport.

\section{INTRODUCTION}

$\mathbf{R}$ elevance of the problem. The collaboration and competition capabilities are related to marginal elements of social relations and they must be coordinated if they are manifested simultaneously. According to Matzdorf and Sen (2015), such interactions as competition, collaboration, negotiations and team work are obligatory for the performance of dance in dancesport. Cerny and Mannova (2011) also state that collaboration and competition are two marginal elements of social relations and they must be coordinated if they act simultaneously. It accentuates and confirms the complicacy of these two social capabilities and their necessity on striving for the harmony of capabilities in dancesport.

Thus, proper coordination of collaboration and competition enables getting a better result. The content of the above-mentioned interactions consists of social capabilities - result of the social and educational interaction. As different social capabilities can be obtained when doing sports (Šniras \& Malinauskas, 2014), it can be supposed that the social capabilities obtained in the sport activity can be transposed to other fields of life and encourage the development of a harmonious personality. It substantiates the significance of 
the research of the coordination of collaboration and competition capabilities on the basis of the dancesport activity.

The problem question was what the educational presumptions of the coordination of collaboration and competition capabilities in the dancesport activity are.

Accordingly, the research aim was to reveal the conceptual model of the educational presumptions of the coordination of collaboration and competition capabilities.

\section{METHODS}

Endeavouring to achieve the aim of the article, theoretical analysis and synthesis was provided: scientific insights into the theory of Social Interdependence were analysed, interrelation between collaboration and competition revealed, afterwards, the theoretical implications on collaboration and competition collaboration were provided. Consequently, the obtained results of theoretical analysis were generalized and incorporated into the conceptual model. The educational presumptions of the coordination of collaboration and competition capabilities were emphasized.

\section{RESULTS}

Collaboration and competition capabilities in the sport activity. Schottle, Haghsheno, and Gehbauer (2014) provided the definition of "collaboration" and indicated the collaboration is organizational relations for common goals in the execution of the common organized activity based on the mutual trust and joint forces on solving arising problems together. It is participation in a planned process with distributed duties, risk and remuneration among its participants. This kind of definition can be adapted in the sport activity involving all signs of a professional activity with the most important goal - to win, be leader in the sport or its group.

The research performed by Arends (1998) confirms that three tendencies can be noticed in the collaboration: there are interdependent relations; members become friends for the common activity in the group; acting together, the collaboration is especially effective - it encourages creating ideas and affecting each other to a wider extent.

Appley and Winder (1977) defined collaboration as a system of human relations with the following values: individuals have a common goal and common limits of acting in the group; the interaction among individuals is based on honesty and justice; the above-mentioned goals are defined by awareness of motives of each individual, understanding of each other and commitment to act together for the committed thing or reached goal. It can be supposed these tendencies of collaboration are characteristic to the sport activity.

Analysing the manifestation of leadership capabilities in the sport activity, Extejt and Smith (2009) defined collaboration as team work effective work with teams or their influence beyond the team: striving for organizational purposes; acts related with the regard of needs of other people and mutual assistance; unification and observation of agreements; coordination of personal goals with goals of the organization or team. In team sport, the collaboration can cause a special physical and positive emotional state when the internal needs are satisfied fully. Xiong (2012) indicates that the coordination of technique and tactics as well as its result in the sport activity usually depend on the psychological preparation of sportspeople to collaborate. They treat the collaboration in the sport activity as a psychological feature of the coordination of intentions that also affects the concentration in the team.

Mattessich and Monsey (1992) defined cooperation as informal relations that are not based on a common mission or planned efforts. Meanwhile, collaboration interconnects into a common structure with the obligation to reach the common goal. Thomson and Perry (2006) note the collaboration grants a higher level of collective acts than cooperation. Meanwhile, Denise (1999) noticed that cooperation is the strategy of attainment of the competitive advantage. Polenske (2004) accentuates higher interdependency between cooperation and competition and states that cooperation and collaboration can almost be identical in certain cases. Some scientific studies explain the differences between cooperation and collaboration by using the dimensions of uninterruptable integration, commitment and complicacy. They relate collaboration with a high level of integration, commitment and complicacy and cooperation - with a low level of integration, commitment and complicacy (Mattessich \& Monsey, 1992; Thomson \& Perry, 2006).

Schottle, Haghsheno and Gehbauer (2014) interconnect collaboration, cooperation and competition into a certain communication system together with coordination, conflicts, commu- 
nication, management, commitment, agreement and compromise. The authors of the system explain cooperation and collaboration as an interaction among participants and coordination as a constituent of cooperation and collaboration and not an independent relation. Kadefors (2004) indicates that cooperation is closely related with management and collaboration - with trust. Activity participants have closer and stronger relations in the collaboration because their common goal and commonly performed activity are based on the trust and openness.

A concrete sport activity can be defined as an organized activity when two or more individuals or teams compete for an award observing certain rules (Chick, 1984). Competition can be one of external social factors and it can have both the positive and negative influence on motivation. Competing sportspeople compare their capabilities and possibilities with their rival in the same sport activity.

Deci and Olson (1989) determined that competition can be interacting (in the defence and offence). In the sport activity, competition is manifested as a victory (one party wins and the other one must lose a victory). In the case of this competition, awards (money, prizes or points) are distributed among participants unevenly, taking into account the results of their performance (for example, the sportsperson that wins the first position gets more points than that taking a lower position).

The mentioned theoretical provisions enable drawing a conclusion that collaboration and competition capabilities are obligatory in the sport activity. Moreover, there is a relation between sport and social capabilities. A sportsperson often becomes activity object and subject in the sport activity: according to his/her capabilities, the sportsperson must solve various issues related with the force, endurance or physical ability as well as tactic tasks, make decisions, collaborate and compete in order to reach sport goals.

Empirical learning as model of the educational presumptions in the dancesport activity. Galanis, Mayol, Forment, and García-Peñalvo (2015) indicate that the interaction among people is very important for informal learning. The sport activity is inseparable from the interaction among people. Informal learning is related with the activity and experience very closely. It is also significant in the context of the sport activity on analysing the empiric learning as basis of the educational presumptions.
Empiric learning is based on three presumptions (Smith, 1980): people learn best when they are involved in empiric learning personally; an individual masters (learns) the knowledge when it is important for the individual or changes the individual's behaviour; a person has the biggest incentives to learn when the person chooses the goals of learning freely and is inclined to strive for them systematically.

The conclusions of the research performed by Harun and Salamuddin (2014) confirmed that empiric learning during the physical activity is basis of the development of social capabilities. The works of other scientists (Del Val Núñez, Romero, Sánchez, \& Aránega, 2018; Muñoz Campos, 2017) also confirm the development of social capabilities during empiric learning. Moreover, Dewey (1938) stated experience is very important for the development of capabilities and acceleration of socialization processes.

De Carteret (2008) indicates that empiric learning takes place during the application of social capabilities, i.e., in the practice, conversations, on taking responsibility or in the cooperation. Cullen, Batterbury, Foresti, Lyons, and Stern (2000) published the conclusions of the research that empiric learning can help to raise the selfconfidence of individuals and improve their social capabilities. Madrona et al. (2014) confirmed social capabilities are also developed during the trainings that meet the conception of empiric learning. This research allows stating that empiric learning is a suitable form of education for the development of social capabilities.

To sum up, it can be presumed that the sport activity is closely related with empiric learning and social capabilities can be developed in it. The basis of the educational interaction of empiric learning is learning by means of experience (during the sport activity). The condition of this kind of learning in the context of empiric learning is circumstances of the activity that all together can be considered educational presumptions and the activity itself becomes education.

Coordination of collaboration and competition capabilities in the dancesport activity. Collaboration and competition were considered incompatible in the theory of educational science for a long time, but it has been stated recently (Bennett \& Kottasz, 2011; Muijs \& Rumyantseva, 2014) that collaboration is manifested in the environment of learning, which competition is also characteristic 
to. Clarke-Hill, Li, and Davies (2003) indicate that collaboration between partners is an undoubtedly important organizational way of learning.

Collaboration is not always successful. Schottle, Haghsheno and Gehbauer (2014) revealed that collaboration among partners is mostly affected by trust, communication, commitment, openness, sharing the knowledge and information, agreements and determination to risk. Malcolm (2014) noted the benefits of collaboration and competition in sport are related.

Competition in sport is a factor of the encouragement of sport mastery. Ainscow, Muijs, and West (2006) suggest that collaboration is possible and increases when competing. The duality of competition and collaboration is used for the explanation of this phenomenon and the term "coopetition" is used to name the phenomenon itself; it is described with interorganizational relations when one part of relations is determined by competition and the other one - by collaboration (Brandenburger \& Nalebuff, 1996). In this case, the advantages of competition are manifested in collaboration and coopetition means the coordination of collaboration and competition capabilities.

Xiong (2012) confirmed that every sportsperson of team sports only focuses on the own personality on striving for sport goals and performing set tasks (he/she tries to reveal (represent) (position) the own personality and ignores collaboration). These results of the research are important because they enable stating that sportspeople compete for their personal goals even if they collaborate in a team. Thus, it is necessary for a sportsperson to coordinate collaboration and competition.

Attle and Baker (2007) emphasize that both competition and collaboration have a potential effect on a learner's behaviour. Moreover, there is an insight that these opposite kinds of behaviour should be coordinated. In turn, collaboration and competition among individuals ensure a successful activity, so the success of individuals becomes useful for the total team (Cerny \& Mannova, 2001). The authors draw a conclusion that a couple of dancers as a sport team has analogical characteristics: successful performances are only possible on participating of the most capable rivals, collaborating (cooperating) in a team, participating in matches and using the own potential to win.

Cooperation can be reached if the participants of relations act separately according to their tasks and contribute to the common result with their activity; meanwhile, collaboration should be understood as a direct interpersonal interaction, common acting together, negotiations, discussions as well as coordination of different future plans. According to the conception of cooperation by Zineldin (2004), it can be envisaged that collaboration involves cooperation and coordination. It emerges that collaboration is possible among individuals in one group (for example, in a couple of dancers) in order to reach personal goals of these individuals and those of the team (couple). Meanwhile, cooperation takes place between two or among more separate individuals (not belonging to one group (team)) or groups (teams) striving for their personal specific and common goals.

Thomson and Perry (2006) prove that cooperation for the sake of the common goal leads to collaboration. Accordingly, collaboration is defined as an activity during that independent people interact and overcome known and unknown difficulties and they together create the rules of their relations as well as structures and ways how to behave or solve the problems determining the common activity.

D. W. Johnson, R. T. Johnson, and Tjosvold (2012) believe that negative interdependency of people conditions the interaction of opposition or competition. It can be manifested as efforts to preclude a rival from reaching the goal or prevent him/her from striving for results, hiding of resources and information from each other, behaviour of mistrust and jealousy. Coakley (1997) defines competition as a social process that is ended with a victory after comparing results in the same activities or performing the same tasks.

The coordination of collaboration and competition capabilities as an interaction of dancesport dancers is manifested at two levels: inside a group (level of a couple of dancers) and among groups or couples (level of the community). Second, the social interdependency of dancers is conditioned by the structure of strived goals: individual, group (of a couple of dancers), communal (of the sport community) ones. Third, depending on the forms of the interrelation among dancers in the sport activity, the social interdependency depends on certain forms of their interaction: collaboration and competition. Moreover, there is a possible combination of the both forms of the interaction. Taking into account this fact, it can be concluded that the relation between collaboration and competition can be manifested simultaneously by coopetition as a higher form of interdependency. 
Theoretical model of the educational presumptions of the coordination of collaboration and competition capabilities in dancesport. The theoretical model of the educational presumptions of the coordination of collaboration and competition capabilities in dancesport is constructed on the basis of the theory of social interdependency. It was determined in this work that collaboration and competition capabilities are manifested in dancesport together and simultaneously and the harmony of these capabilities is characteristic of this kind of manifestation. When at least two individuals interact, there is a certain interrelation between them. The type of this relation depends on the situation the individuals interact in (Holmes, 2002). In our work, in the case of dancesport, these relations are also circumstances of the activity as well as educational presumptions.

The pioneer of the theory of social interdependency Deutsch (1949) determined two types of interdependency: positive and negative ones. According to D. W. Johnson and R. T. Johnson (2009), positive interdependency means that people, who strive for their goal, have a positive attitude: they understand that it is only possible to reach the goal if the other individuals they are related in collaboration relations with will reach their goals, too. In the dancesport activity, positive interdependency among dancers is determined by successful common work in a team (couple of dancers) and competition against rivals in matches on striving for the leadership (recognition). Positive interdependency is encouraged by the interpersonal interaction.

According to Choi, D. W. Johnson and R. T. Johnson (2011), positive interdependency is inseparable from collaboration in the community. Negative interdependency means a negative interpersonal relation among people striving for their goals: the individuals understand that they can only strive for their goals if the other individuals they are related in competition relations with will stumble and not reach for their goals (D. W. Johnson $\&$ R. T. Johnson, 2009). Negative interdependency is also characteristic to the match interaction. Choi, D. W., Johnson and R. T. Johnson (2011) think that negative interdependency is manifested under the conditions of competition.

Enjolras and Waldahl (2007) believe that in order to keep interrelations in sport, they must be useful. D. W. Johnson and R. T. Johnson (2005) suggest that it is insufficient to understand positive or negative interdependency. People must make sure of it in reality on striving for their goal with certain acts. These acts are useful under the circumstances of collaboration (encouraging acts) or under the circumstances of competition (a rival's acts are inhibited). Thus, dancesport dancers that support each other in a couple and work together strive for international recognition and leadership in global ratings and try to overcome their rivals.

The performed analysis of scientific literature enables envisaging the educational presumptions of the coordination of collaboration and competition capabilities in dancesport manifested as coopetition. First, the dancesport activity by itself is an educational activity in a sense of empiric learning. Second, the circumstances of the dancesport activity are educational conditions identified with educational presumptions in this work. Thus, the circumstances of the activity that are significant for the coordination of collaboration and competition capabilities must be accentuated in the dancesport activity.

Essential characteristics of dancesport: sport and competitive ones. The essential criterion of the assessment of dancesport is aesthetics (Soraka, 2007) and it is related with feelings and experiences. Of course, not all the circumstances of the dancesport activity are significant for the coordination of collaboration and competition capabilities in dancesport. The effect on the coordination of collaboration and competition capabilities of dancers is only determined by certain circumstances of the activity and they must be revealed. It was indicated that the basis of collaboration and competition is a social concept. In turn, the major part of the social interaction is based on an individual's communication that is determined by communication capabilities. It allows drawing a conclusion that collaboration and competition capabilities are closely related with interpersonal interaction and communication capabilities. The interpersonal interaction is both exchanging of information in a non-verbal form that can change the partner's behaviour and organization of common acts. Thus, the interpersonal interaction is closely related with collaboration and cooperation. Moreover, this interaction can change the partner's behaviour in a non-verbal form, too, because it is closely related with competition and strategy of strived goals. Besides, social relations are emphasized in the structure of the interpersonal interaction: spatial contacts, psychological contacts, social contacts and social relations. They also affect collaboration and competition capabilities and coordination of these capabilities. 
The performed analysis of scientific literature confirmed that goals are essential objects of the interpersonal interaction. Sportspeople's goals and their structure condition the peculiarities of the interpersonal interaction among sportspeople: they condition competition and collaboration; sportspeople encounter different types of relations and these relations are even inspired by opposite goals. As a result of these relations, collaboration and competition capabilities must be coordinated. In the case of dancesport, the goals of a couple of dancers are accentuated in the structure of goals next to the personal goals of sportspeople. Thus, sportspeople can have different interactions in the sport activity: in a group (couple of dancers) and among groups (couples of dancers); moreover, when dancers interact, they can strive for individual, group and communal goals. In turn, the interactions of dancers in the dance activity are conditioned by sport and other goals and their synthesis is an obligatory condition to reach desired results.

To sum up the results of this work, the following obligatory educational conditions of the coordination of collaboration and competition capabilities in dancesport manifested as coopetition can be indicated: interpersonal interaction, presence of the community, team work in a couple, expressive creative activity (improvisation in dancing and choreography and creativity in dance halls encourage special collaboration and provide with experience of collaboration), competition, friendly and benevolent environment, common work in dance halls, striving for sport goals (personal, pair and/or communal ones), collaboration in a couple, responsibility, commonness, coordination of mutual decisions and acts, simultaneous collaboration and competition.

The accentuated educational conditions as presumptions can be interconnected by providing the theoretical model of the educational presumptions of the coordination of collaboration and competition capabilities based on social interdependency (see Figure).

The following groups of the educational presumptions of the coordination of collaboration and competition were accentuated in the compiled model on the basis of theoretical insights: independent educational conditions defined by the following interactions - relations (they determine coopetition in competition, matches, cooperation, achievements, trust and collaboration): personal goals of dancers; relations inside the club; relations beyond the club; dependent educational conditions defined by the following interactions - relations (they determine coopetition directly or each through other including trust): achievements, matches, trust, competition, cooperation, collaboration.

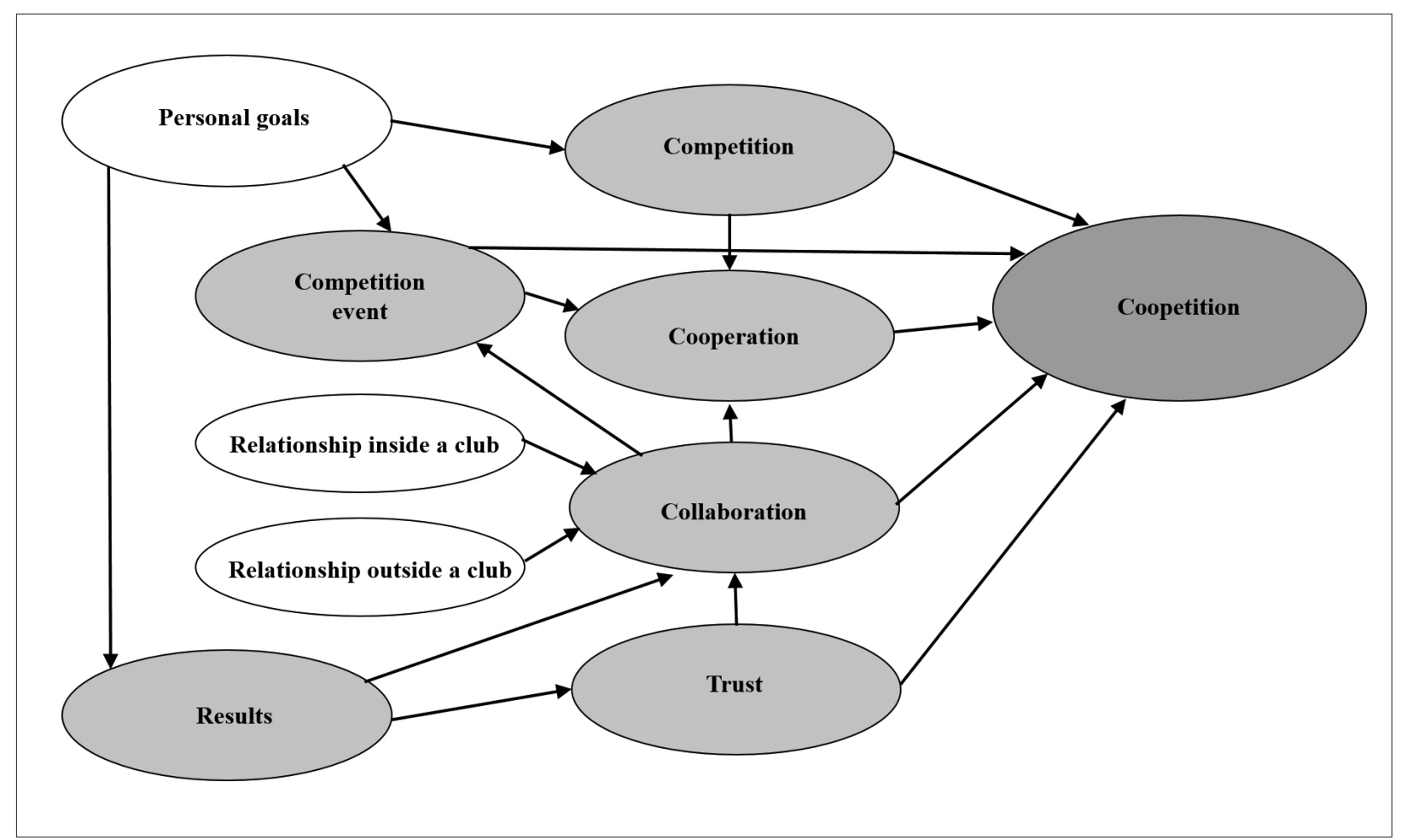

Figure. Theoretical model of the educational presumptions of the coordination of collaboration and competition (Armas, 2016) 


\section{DISCUSSION}

The sport and competitive characteristics of dancesport are accentuated most. The name of dancesport as a sport activity accentuates sportsmanship that cannot be imagined without matches, i.e., contention among dancers (competition).

Năstase (2012) defines dancesport as a kind of pair sport, which result is assessed with a subjective score and which acts must be coordinated (exact collaboration in a certain segment of time). The aesthetical criterion is decisive in the assessment of dancesport (Soraka, 2007). Physical and artistic capabilities in dancesport are manifested together with social ones and constant use of capabilities enables developing them.

Matzdorf and Sen (2015) performed a scientific study in order to reveal the elements of dancers' leadership and following and determine the way of relation between these phenomena and activity of organizations. In order to reach the goal, the researchers also provided examples from the practice of dancers and coaches stating that the interaction, such as competition, collaboration, coordination and team work, is obligatory for dancers. The scientists determined an important trait of dancesport - to feel the space in different ways including the management of competition and collaboration situations simultaneously. This important statement confirms that the environment of dancesport is suitable for the manifestation of such forms of the interaction as competition, collaboration, coordination and team work. It confirms that the management of collaboration and competition is obligatory and must be simultaneous. Meanwhile, Pytlik (2009) states that dancesport has an influence on social processes: encourages competing expeditiously and singlemindedly in a friendly and benevolent environment. Moreover, he accentuates that it is not only sport as a physical education program, but also a kind of universal activity: the posture, character, respect to the other sex and favourable interaction among people are developed.

Schupp (2015) proved with his research that learning in dance classes by using collaboration capabilities can prepare students for the practical activity of life beyond the scientific institution better including the career possibilities. In turn, the improvisation in dancing and choreography and creativity in dance halls encourage special collaboration and provide with experience of collaboration.
Smith and Betts (2000) confirm that the activity and results of a learning group will be more effective if the group members also use the principles of striving for their personal goals in their collaboration. They revealed in the study that the principles of striving for personal goals in collaboration were only effective if they also improved the results of a separate individual. According to the principles of striving for personal goals, all members of a collaborating group must be independent and free since the very beginning of their activity on striving for the common goal.

Pavlidou, Sofianidou, Lokosi, and Kosmidou (2018) determined that collaboration in a couple, responsibility and a sense of commonness are important for the relations of communication in dancing. Moreover, the authors emphasize an especially important role of the teacher (coach) as he/ she interacts with dancers and can affect and manage the communication process by motivating, consulting, praising, disciplining or giving other advice.

The dance interaction is a reflective process involving partners of a couple, their coaches and surrounding social environment. The effectiveness of the interaction depends on the closeness of relations among interacting people and their communicative capabilities (Jovaiša, 2007). When dancers work together (in a couple), they must be sensitive and attentive to moves of each other and coordinate their mutual decisions and acts sometimes (interpersonal interaction capabilities).

McCabe, Wyon, Ambegaonkar, and Redding (2013) analysed the contribution of scientists into the research of dancesport in order to help to understand dancesport dancers better. This study revealed some interesting generalizations. First, they emphasized the self-expression, performance, sportsmanship and social relations as some of the motives to do dancesport. Moreover, the dancers said that dancesport is full of narcissism and competition. Second, dancesport is a kind of competitive sport related with the monetary prize fund and world rating. Thus, the motivation in the sport activity is directed to the physical improvement of the sport performance because the benefit obtained by dancers (prizes, fame, world recognition etc.) can depend on the culture of competition in dancesport.

It can be concluded that the development of sport capabilities in dancesport takes place together with the development of artistic capabilities when art helps to perform social roles. The conception of artistic education based on the effect of the environment 
and interpersonal interaction as well as social interdependency confirms the educational presumptions of dancesport. The interpersonal interactions of dancers experienced in dancesport, such as collaboration, competition and coordination, make the theoretical basis of empiric learning. As it is necessary in dancesport to manage collaboration and competition situations simultaneously, it allows stating that the coordination of these capabilities is experienced.

\section{CONCLUSIONS}

The theoretical model of the educational presumptions of the coordination of collaboration and competition in dancesport reveals the conceptual basis of the educational presumptions of the coordination of collaboration and competition in dancesport. The level of compatibility of collaboration and competition in dancesport and its essential structural parts can be analysed taking into account the interpersonal relations of dancers in a certain situation. Besides, the structural elements of collaboration and competition can be determined and adapted to concrete situations in the dancesport activity.

Dancesport dancers act and strive for sport and personal goals by using collaboration and competition capabilities, coordinating them and reaching the higher form of coopetition (harmony). The educational presumptions of the coordination of collaboration and competition in dancesport are based on the analysis of literature about the forms of the interpersonal interaction both in the social environment and sport activity, manifestation of discussed forms of the interaction and theory of empiric learning including capabilities.

\section{REFERENCES}

Ainscow, M., Muijs, R. D., \& West, M. (2006). Collaboration as a strategy for improving schools in challenging circumstances. Improving Schools, 9(3), 1-11.

Appley, D. G., \& Winder, A. E. (1977). An Evolving Definition of Collaboration and Some Implications for the World of Work. The Journal of Applied Behavioral Science, 13(3), 279-291.

Arends, R. I. (1998). Mokomès mokyti. Vilnius: Margi raštai.

Armas, A. (2016). Sportsmen coopetition: A case of international dance-sport competition. Acta Kinesiologiae Universitatis Tartuensis, 22, 57-69.

Attle, S., \& Baker, B. (2007). Cooperative learning in a competitive environment: Classroom international. Journal of Teaching and Learning in Higher Education Applications, 19(1), 77-83.

Bennett, R.A., \& Kottasz, R.(2011). Strategic, competitive and cooperative approaches to internationalisation in European business schools. Journal of Marketing Management, 27(11-12), 1087-1116. https://doi.org/ 10.1080/0267257X.2011.609131

Brandenburger, A., \& Nalebuff, B. (1996). Co-opetition: $A$ revolution mind-set that combines competition and collaboration. Cambridge: Harvard business Press.

Cerny, T., \& Mannova, B. (2011). Competitive and collaborative approach towards a more effective education in computer science. Contemporary Educational Technology, 2(2), 163-173.

Chick, G. E. (1984). The cross-cultural study of games. Exercise and Sport Sciences Reviews, 12, 307-337.

Choi, J., Johnson, D. W., \& Johnson, R. (2011). Relationships among cooperative learning experiences, social interdependence, children's aggression, victimization, and prosocial behaviours. Journal of
Applied Social Psychology, 41(4), 976-1003. https://doi. org/10.1111/j.1559-1816.2011.00744.x

Clarke-Hill, C., Li, H., \& Davies, B. (2003). The paradox of co-operation and competition in strategic alliances: Towards a multi-paradigm approach. Management Research News, 26(1), 1-20. doi: 10.1108/01409170310783376

Coakley, J. J. (1997). Sport in society: Issues and controversies (6th ed.). Irwin, CA: McGraw-Hill.

Cullen, J., Batterbury, S., Foresti, M., Lyons, C., \& Stern, E. (2000). Informal learning and widening participation. London: DfEE.

De Carteret, P. (2008). Diverse pleasures: Informal learning in community. Australian Journal of Adult Learning, 48(3), 502-521.

Deci, E. L., \& Olson, B. C. (1989). Motivation and competition: Their role in sports. In J. H. Goldstein (Ed.), Sports, games, and play (pp. 83-110). Hillsdale, NJ: Erlbaum.

Del Val Núñez, M. T., Romero, F. J. C., Sánchez, R. C., \& Aránega, A. Y. (2018). Developing management skills through experiential learning: The effectiveness of outdoor training and mindfulness. European Journal International Management, 12(5/6), 676-694. https:// doi.org/10.1504/EJIM.2018.094473

Denise, L. (1999). Collaboration vs. c-three (collaboration, coordination, and communication). Innovating, 7(3), 1-6.

Deutsch, M. (1949). A theory of collaboration and competition. Human Relations, 2, 129-152.

Dewey, J. (1938). Experience and education. New York: Macmillan.

Enjolras, B., \& Waldahl, R. H. (2007). Policy-making in sport: The Norwegian case. International Review for the Sociology of Sport, 42(2), 201-216. https://doi. org/10.1177\%2F 1012690207084753 
Extejt, M. M., \& Smith, J. E. (2009). Leadership development through sports team participation. Journal of Leadership Education, 8, 224-237.

Galanis, N., Mayol, E., Forment, M., \& García-Peñalvo, F. (2015). Designing an informal learning support framework. TEEM '15 Proceedings of the 3rd International Conference on Technological Ecosystems for Enhancing Multiculturality, 461-466.

Harun, M. T., \& Salamuddin, N. (2014). Promoting social skills through outdoor education and assessing its effects. Asian Social Science, 10(5), 71-78. https://doi.org/10.5539/ ass.v10n5p71

Holmes, J. G. (2002). Interpersonal expectations as the building blocks of social cognition: An interdependence theory perspective. Personal Relationships, 9(1), 1-26. https://doi.org/10.1111/1475-6811.00001

Johnson, D. W., Johnson, R. T. (2009). An educational psychology success story: Social interdependence theory and cooperative learning. Educational Researcher, 38, 365-379.

Johnson, D. W., \& Johnson, R. T. (2005). New developments in social interdependence theory. Genetic, Social \& General Psychology Monographs, 131(4), 285-358. https://doi. org/10.3200/MONO.131.4.285-358

Johnson, D. W., Johnson, R. T., Tjosvold, D. (2012). Effective collaboration, the foundation of sustainable peace. In P. T. Coleman, M. Deutsch, Psychological components of sustainable peace: An introduction (pp. 21-40). New York: Springer Science+Business Media.

Jovaiša, L. (2007). Enciklopedinis edukologijos žodynas. Vilnius: Gimtasis žodis.

Kadefors, A. (2004). Trust in project relationships inside the black box. International Journal of Project Management, 22(3), 175-182. https://doi.org/10.3200/ MONO.131.4.285-358

Madrona, P. G., Samalot-Rivera, A., Cristina, E., Marín, G., Rodenas-Jiménez, J., \& Rodenas-Jiménez, L. (2014). Improving Social Skills through Physical Education in Elementary 4th Year. American Journal of Sports Science and Medicine, 2(6A), 5-8. doi: 10.12691/ajssm-2-6A-2

Malcolm, D. (2014). The social construction of the sociology of sport: A professional project. International Review for the Sociology of Sport, 49(1), 3-21. https://doi. org/10.1177\%2F1012690212452362

Mattessich, P. W., \& Monsey, B. R. (1992). Collaboration: What makes it work. Saint Paul, MN: Amherst H. Wilder Foundation.

Matzdorf, F., \& Sen, R. (2015). Dance, leadership and space. Conference: EGOS Colloquium 2015, At ALBA Graduate Business School at the American College of Greece, Athens. 1-15.

McCabe, T. R., Wyon, M., Ambegaonkar, J. P., \& Redding, E. (2013). A bibliographic review of medicine and science research in DanceSport. Medical Problems of Performing Artists, 28, 70-79.

Muñoz Campos, D. (2017). Problem-based learning: An experiential strategy for English language teacher education in Chile. PROFILE Issues in Teachers' Professional Development, 19(1), 29.

Muijs, D., \& Rumyantseva, N. (2014). Coopetition in education: Collaborating in a competitive environment. Journal of Educational Change, 15(1). doi: 10.1007/ s10833-013-9223-8

Năstase, V. (2012). Theoretical design definition of dance sport. Procedia - Social and Behavioral Sciences, 51, 888890.

Pavlidou, E., Sofianidou, A., Lokosi, A., \& Kosmidou, E. (2018). Creative dance as a tool for developing preschoolers' communicative skills. European Psychomotricity Journal, 10, 3-15.

Polenske, K. R. (2004). Competition, collaboration and collaboration: An uneasy triangle in networks of firms and regions. Regional Studies, 38(9), 1029-1043. https://doi. org/10.1080/0034340042000292629

Pytlik, G. (2009). Promoting public health through dance: Dancesport as an integrated component of sport and healthy living in $B C$. Richmond, British Columbia, Canada: Dancesport BC.

Schottle, A., Haghsheno, S., \& Gehbauer, F. (2014). Defining collaboration and collaboration in the context of lean construction. In: Proceedings 22nd Annual Conference of the International Group for Lean Construction. Oslo, Norway (pp. 1269-1280).

Schupp, K. (2015). Teaching collaborative skills through dance: Isolating the parts to strengthen the whole. Journal of Dance Education, 15(4), 152-158. https://doi.org/10.108 $0 / 15290824.2015 .1039643$

Smith, M. K. (1980). Creators Not Consumers: Rediscovering social education. Leicester: National association of Youth Clubs.

Smith, R., \& Betts, M. (2000). Learning as partners: Realising the potential of work based learning. Journal of Vocational Education and Training, 52(4), 589-604. https://doi.org/10.1080/13636820000200141

Soraka, A. (2007). Buitinis šokis. Klaipèda: Klaipėdos universiteto leidykla.

Šniras, Š., \& Malinauskas, R. (2014). Sportininku ir trenerio saveikos psichologija: studiju knyga. Kaunas: Lietuvos sporto universitetas.

Thomson,A. M., \& Perry, J. L. (2006). Collaboration process: Inside the black box. Public Administration Review, 66, 2032. https://doi.org/10.1111/j.1540-6210.2006.00663.x

Xiong, J. (2012). The functions and methods of mental training on competitive sports. Physics Procedia, 33, 20112014. doi: 10.1016/j.phpro.2012.05.316

Zineldin, M. (2004). Co-opetition: The organisation of the future. Marketing Intelligence \& Planning, 22(6/7), 780-789.
Corresponding author Audrius Armas

Department of Health, Social and Physical Education

Lithuanian Sports University

Sporto str. 6, LT-44221 Kaunas

Lithuania

Tel. +37069946944

Email audarm@stud.1su.lt 